\title{
Zeolite A Synthesis Employing a Brazilian Coal Ash as the Silicon and Aluminum Source and its Applications in Adsorption and Pigment Formulation
}

\author{
Lindiane Bieseki ${ }^{\mathrm{a}}$, Fábio Garcia Penha ${ }^{\mathrm{b}}$, Sibele Berenice Castellã Pergher ${ }^{\mathrm{a}}$
}

\author{
aLaboratório de Peneiras Moleculares - LABPEMOL, \\ Programa de Pós-graduação em Ciência e Engenharia de Materiais, \\ Universidade Federal do Rio Grande do Norte - UFRN, \\ CEP 59078-970, Natal, RN, Brasil \\ 'Instituto Federal de Educação, Ciência e Tecnologia do Rio Grande do Norte - IFRN, \\ CEP 59900-000, Pau dos Ferros, RN, Brasil
}

Received: April 3, 2012; Revised: July 13, 2012

\begin{abstract}
Zeolite A was synthesized using the coal ash from Siderópolis/RS - Brazil. The synthesis was based on a standard IZA synthesis using coal ash as the $\mathrm{Si}$ and $\mathrm{Al}$ source. XRF analysis showed that the coal ash has a $\mathrm{Si} / \mathrm{Al}$ ratio of 1.52 , which is close to the $\mathrm{Si} / \mathrm{Al}$ ratio required to produce zeolite $\mathrm{A}(1.0)$. The synthesized materials were analyzed by XRD, SEM and $\mathrm{N}_{2}$ adsorption. More crystalline materials were obtained during synthesis when an additional treatment was applied at a temperature of $353 \mathrm{~K}$ at the dissolution of $\mathrm{NaOH}$ step. The product formed after 4 hours was the most crystalline, but even the product formed after 1 hour proved to be better than that formed using the standard 4 hours IZA synthesis. The zeolites synthesized by this method had an adsorption capacity of $120 \mathrm{mg} \cdot \mathrm{g}^{-1} \mathrm{for} \mathrm{Ca}^{2+}$, half the capacity of commercial zeolite A $\left(300 \mathrm{mg} \cdot \mathrm{g}^{-1}\right)$. It was not possible to obtain blue or green pigments using the synthesized zeolite $\mathrm{A}$.
\end{abstract}

Keywords: zeolite A, coal ash, adsorption, pigment

\section{Introduction}

Energy production by the combustion of coal generates by-products containing fly ash. According to Fungaro and Silva ${ }^{1}$, in pulverized coal boilers, over three quarters of the ash produced is light enough to be dragged along with the combustion gases. The remaining fly ash is dense and remains at the bottom of the boiler, merging into larger particles referred to as bottom or residual ash. Fly ash is generally captured by retention equipment such as an electrostatic precipitator.

Due to its composition (approximately 50 and 30\%wt. of silicon oxide and aluminum), the fly ash can be used as raw materials for the synthesis of zeolites. Different studies have used the ash from burned coal as a source of silicon and aluminum for the synthesis of pure phase zeolites or mixtures of materials. The synthesis of NaP1 zeolites by the hydrothermal treatment of ashes have shown good results for the adsorption of heavy metals ${ }^{2}$. The synthesis of Na-A and Na-X have used hydrothermal treatments ${ }^{3}$ and are associated with alkaline ash fusion ${ }^{4}$. Yaping et al. $(2008)^{5}$ synthesized three different materials, Na-A, Na-X and $\mathrm{NaP} 1$, by alkaline fusion with sodium carbonate, desilification and a hydrothermal process. This synthesis was facilitated by the addition of a structure-driving agent

*e-mail: lindiane.bieseki@gmail.com of zeolite crystals of the desired phase. The fusion method contributes to the formation of more crystalline and higher purity zeolites due to facilitation of the dissolution of $\mathrm{Si}$ and $\mathrm{Al}$ present in the ash ${ }^{4}$. The zeolite $\mathrm{P}$ and zeolite $\mathrm{X}$ synthesized using hydrothermal treatments may show high cation exchange capacities ${ }^{6}$. The zeolite $\mathrm{A}$ and faujasites obtained by the conversion of the coal ash present an ion exchange capacity for $\mathrm{Cs}^{+}$ions of $19 \%$ (zeolite A) and 39\% (zeolite faujasite), in relation to commercial zeolites that present greater ion exchange capacity ${ }^{7}$. Some authors ${ }^{8,9}$ have reported the synthesis of ZSM-5 from rice hull ash. Along with applications in toxic waste recycling, the materials synthesized can be used for the adsorption of heavy metals ${ }^{2,10}$ and the removal of organic compounds ${ }^{11}$.

It can be observed from the literature that it is possible to synthesize different zeolite materials from natural materials or industrial residues, but all processes employ high quantities of $\mathrm{NaOH}$ and high temperatures (alkaline fusion method). These processes are high-cost and sometimes irreproducible.

To reduce temperatures and the amount of reactants required, our group has studied a new method for the synthesis of Zeolite A that employs clays as raw materials. This synthesis was made by modifying the standard IZA procedure and does not use alkaline fusion ${ }^{12}$. 
The objective of this work is to study this new synthetic method for the production of zeolite A using a coal ash from Brazil as the source of silicon and aluminum and to test the resulting materials in adsorption experiments and in the formulation of pigments.Experimental Procedure

The coal ash used in this study was of fly ash and obtained by burning coal mined from Siderópolis/RS - Brazil. The burning was performed in an oven (FORNITEC) at a temperature of $973 \mathrm{~K}$ for 6 hours using a sample of coal with particle diameters from 150 to 300 micrometers.

\subsection{Zeolite A synthesis}

Zeolite A was synthesized by the standard IZA method with extra heating to facilitate the dissolution of $\mathrm{Al}$ and $\mathrm{Si}$ in the sample (coal ash) $)^{13,14}$. The reagents used in the synthesis are described in Table 1.

In each synthesis, $3.9 \mathrm{~g}$ of coal ash were used replacing the $\mathrm{SiO}_{2}$, also $1.9 \mathrm{~g}$ of sodium aluminate were added in the synthesis to adjust the $\mathrm{Si} / \mathrm{Al}$ ratio. In the third step of the synthesis (Table 1), a reaction time of 2 hours at temperature of $353 \mathrm{~K}$ was used. The time of crystallization was also studied over 1, 3 and 4 hours.

\subsection{Pigment synthesis}

Pigments were synthesized according to the following methodology: to $1 \mathrm{~g}$ of zeolite $\mathrm{A}$ was added $0,5 \mathrm{~g}$ of $\mathrm{Na}_{2} \mathrm{CO}_{3}$ and $1 \mathrm{~g}$ sulfur. This mixture was then melted at $773 \mathrm{~K}$ for 20 hours. Subsequently, the solid was washed with distilled water to remove any excess sulfur and dried at $373 \mathrm{~K}^{15}$.

\subsection{Calcium adsorption tests}

$\mathrm{Ca}^{2+}$ adsorption tests were performed using calcium chloride solutions at different concentrations varying from 500 to $3000 \mathrm{mg} . \mathrm{L}^{-1}$ at $298 \mathrm{~K}$ for 1 hour with stirring. A commercial sample of zeolite A and a highly crystalline synthesized sample were evaluated. The $\mathrm{Ca}^{2+}$ quantification was accomplished on a Varian Atomic Absorption Spectrophotometer - model AA. All samples were previously in $\mathrm{Na}$ form.

\subsection{Materials characterization}

X-ray (powder) diffraction (XRD) patterns of different zeolite materials and coal ashes were obtained using a Siemens model D5000 diffractometer with a Ni-filter and $\mathrm{Cu}$ $\operatorname{K} \alpha$ radiation $(\lambda=1.54 \AA)$. Chemical analysis was performed by $X$ ray fluorescence spectroscopy using a Philips - PW 148D. Electron microscopy analysis was performed on a JEOL JSM 6060 scanning electron microscope with a $20 \mathrm{kV}$ acceleration voltage at varying magnifications. BET

Table 1. Synthetic procedure.

\begin{tabular}{cl}
\hline Steps & \multicolumn{1}{c}{ Quantities and reactants employed } \\
\hline 01 & $\begin{array}{l}\left.40 \mathrm{~g} \mathrm{H}_{2} \mathrm{O}+0.3615 \mathrm{~g} \mathrm{NaOH} \text { (divide into } \mathrm{V} 1 \text { and } \mathrm{V} 2\right) \\
02\end{array}$ \\
$\begin{array}{l}\mathrm{V} 1+4.129 \mathrm{~g} \text { sodium aluminate (partly replaced by } \\
\text { coal ash) }\end{array}$ \\
03 & $\begin{array}{l}\mathrm{V} 2+2.235 \mathrm{~g} \mathrm{SiO}_{2} \text { (substituted by the coal ash) }+2.92 \mathrm{~g} \\
\mathrm{NaOH}+3.29 \mathrm{~g} \mathrm{H}_{2} \mathrm{O}\end{array}$ \\
04 & Quickly add V1 into V2 together, mix until homogenized \\
05 & Crystallization at a constant temperature of 373 K \\
\hline
\end{tabular}

specific surface area analysis was performed by nitrogen adsorption using a QuantaChrome NovaWin 2. For this analysis, $100 \mathrm{mg}$ of the samples were pretreated at $573 \mathrm{~K}$ for 3 hours under vacuum.

\section{Results and Discussion}

\subsection{Coal ash characterization}

Elemental analysis by XRF (Table 2) showed that the coal ash has high quantities of $\mathrm{Al}_{2} \mathrm{O}_{3}$ and $\mathrm{SiO}_{2}$, indicating that it is a good source of $\mathrm{Al}$ and $\mathrm{Si}$ for the zeolite synthesis. It should be noted that the presence of cations may influence the composition and structure of the synthesized material, examples may include $\mathrm{Ca}, \mathrm{K}, \mathrm{Fe}$ and $\mathrm{Mg}$. The $\mathrm{Ca}, \mathrm{K}$ and $\mathrm{Mg}$ (exchangeable cations) may interfere with the pore diameter and surface area of zeolite $\mathrm{A}^{12}$. We observed the presence of titanium oxides and sulfur that can remain in the synthesized materials; these impurities may induce to undesired reactions when the materials are used in catalysis. The presence of heavy metals was not observed in the coal ash.

The molar ratio of $\mathrm{Si} / \mathrm{Al}$ from the coal ash obtained from Siderópolis is 1.52, as calculated by XRF. According to Gianetto et al. ${ }^{13}$ the synthesis of zeolite A proceeds best with a mole ratio of $\mathrm{Si} / \mathrm{Al}$ of 1 , so it is necessary to add aluminum (sodium aluminate) to the synthesis mixture.

Figure 1 shows XRD patterns of the coal ash from Siderópolis. The mineral analysis shows the presence of crystalline quartz, alkali feldspar, illite and hematite. These materials may all influence the zeolite synthesis.

\subsection{Zeolite A synthesis}

Figure 2 illustrates XRD patterns and micrographs of materials synthesized by the standard IZA method with (a) and without (b) temperature treatments. Peaks typical of A zeolite A can be found in both samples $\left(2 \theta=7.1^{\circ}\right.$, $10.1^{\circ}, 12.4^{\circ}, 16.1^{\circ}, 21.4^{\circ}, 27.1^{\circ}, 29.9^{\circ}$ and $\left.34.1^{\circ}\right)$. Figure $2 b$ shows the results for the product obtained by the standard IZA synthesis. The presence of peaks with low intensity can be considered an indication of low crystallinity in the corresponding material. The presence of quartz can be observed at $2 \theta=20.9^{\circ}, 26.6^{\circ}$ and $36.5^{\circ}$, indicating that the original quartz present in the coal ash did not react during the formation of the zeolite. The reflexions in $2 \theta=8.8^{\circ}$, $17.6^{\circ}, 19.7^{\circ}$ (Illite) and $33.1^{\circ}$ (hematite) belong to the starting material, and the alkali feldspar was the only part of the precursor not observed in the synthesis product.

Table 2. Chemical analysis data by XRF of the coal ash from Siderópolis.

\begin{tabular}{cc}
\hline Compound & wt\% \\
\hline $\mathrm{Al}_{2} \mathrm{O}_{3}$ & 32.1 \\
$\mathrm{SiO}_{2}$ & 57.7 \\
$\mathrm{~K}_{2} \mathrm{O}$ & 3.8 \\
$\mathrm{Fe}_{2} \mathrm{O}_{3}$ & 3.7 \\
$\mathrm{MgO}$ & 0.5 \\
$\mathrm{SO}_{3}$ & 0.9 \\
$\mathrm{CaO}$ & 0.7 \\
$\mathrm{TiO}_{2}$ & 0.5 \\
\hline
\end{tabular}


As shown in Figure 2a, the use of temperature in step 3 of the synthesis leads to the formation of more crystalline materials. The peaks related to zeolite $\mathrm{A}$ are more intense, indicating that this variation in the synthetic method provides greater dissolution of the $\mathrm{Si}$ and $\mathrm{Al}$ present in the coal ash as required for the zeolite synthesis.
Some authors have employed different treatments using higher concentrations of $\mathrm{NaOH}$, temperature ${ }^{14,15}$ or pretreatment by alkaline fusion ${ }^{3,4}$ to facilitate the dissolution of the $\mathrm{Si}$ and $\mathrm{Al}$ oxides present. The concentration of $\mathrm{NaOH}$ was approximately $3.3 \mathrm{~mol} . \mathrm{L}^{-1}$ in this synthesis. The solid: liquid ratio (in this case coal ash and $\mathrm{NaOH}$ solution)

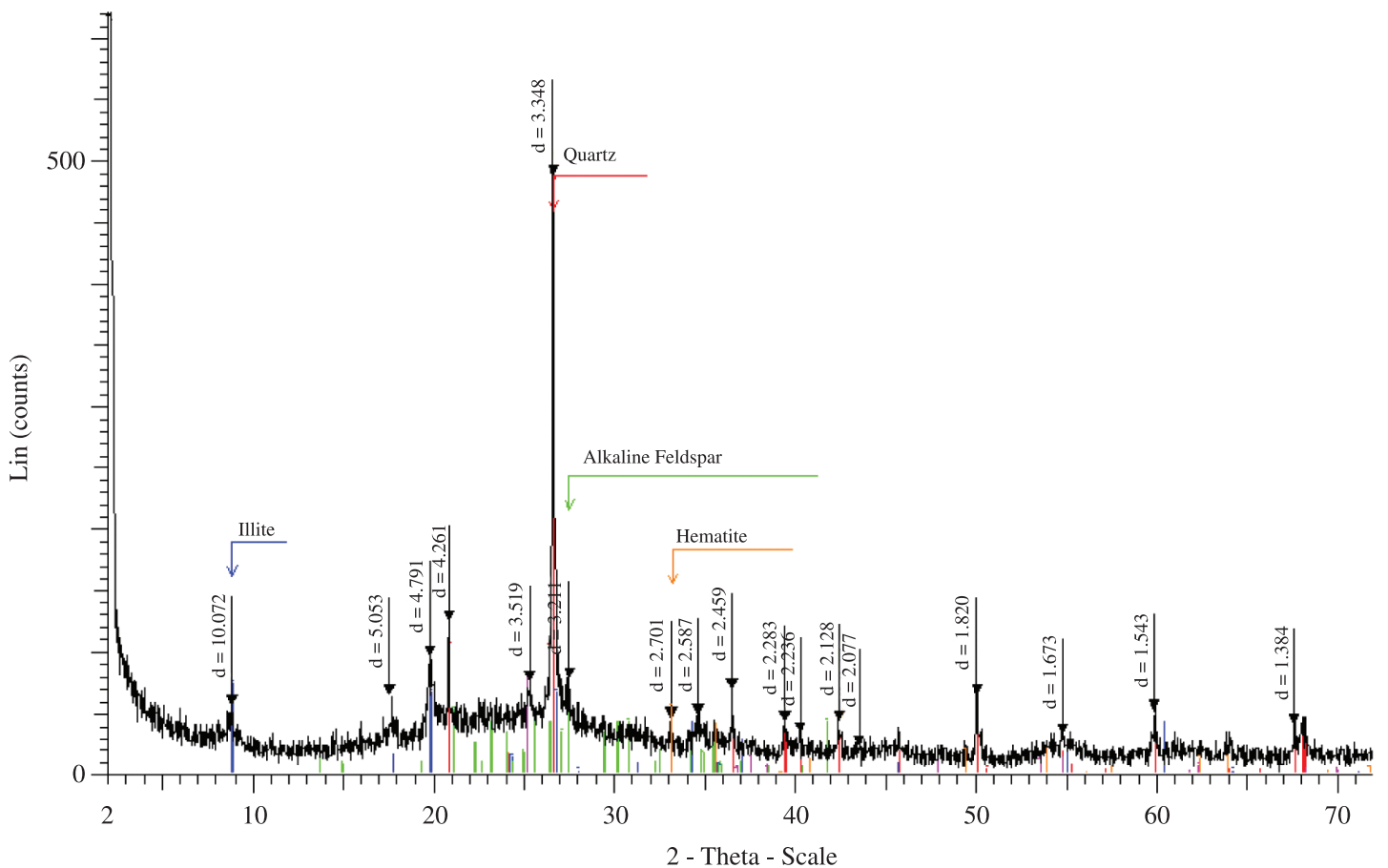

Figure 1. XRD diffractogram of coal ash from Siderópolis.

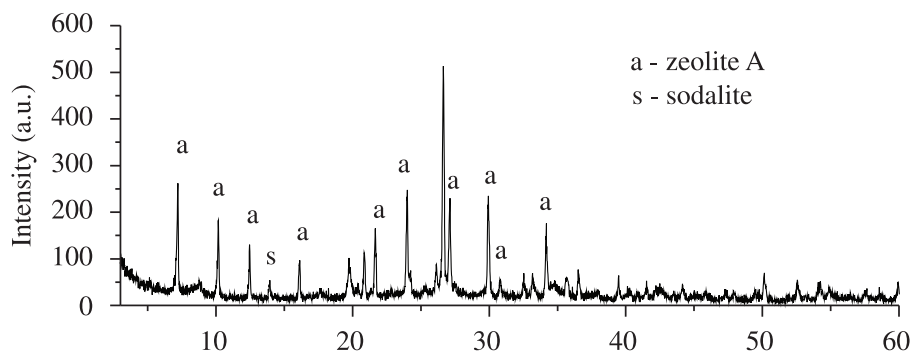

(a)

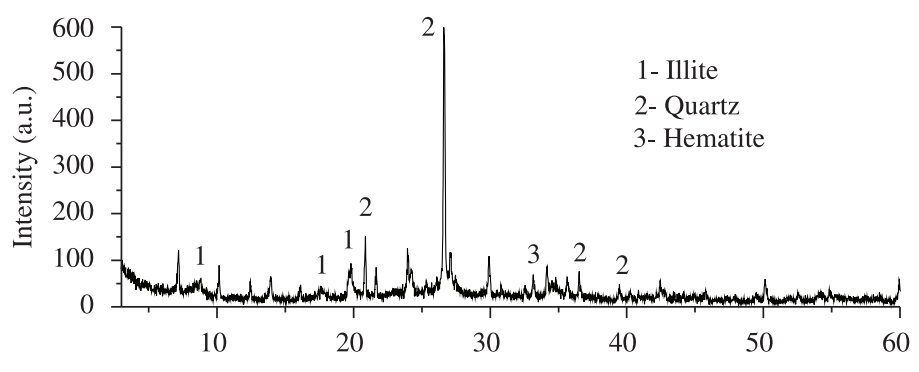

(b)
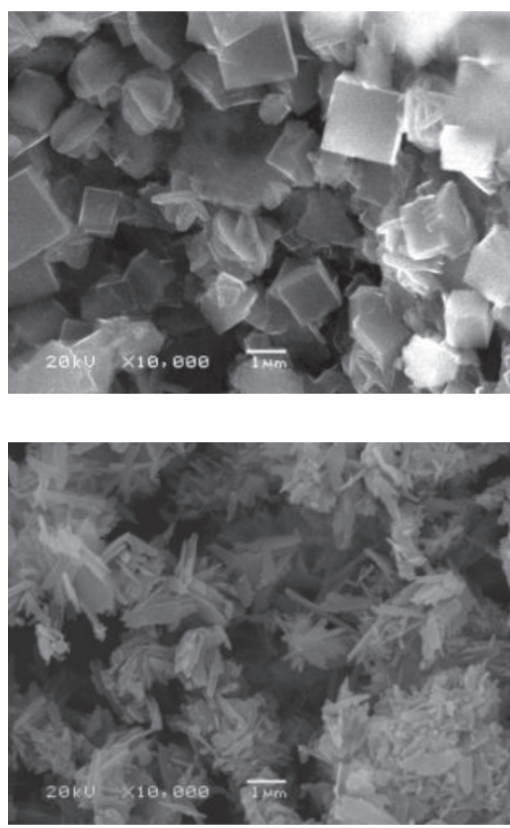

Figure 2. XRD diffractogram and SEM micrographs of zeolite A obtained (a) with a $353 \mathrm{~K}$ temperature treatment for 2 hours during step 3 of the synthesis and (b) Standard synthesis. 
influences the dissolution of the materials. Solid: liquid ratios smaller than $50 \mathrm{~g} . \mathrm{L}^{-1}$ are more favorable for the dissolution of materials, as shown by Walek et al. ${ }^{14}$. In our study, the solid:liquid ratio in step 3 of the synthesis was 167 g. $\mathrm{L}^{-1}$. With the concentration of $\mathrm{NaOH}$ and the solid:liquid ratio used in this study, increases in the reaction time and temperature were necessary to obtain more crystalline materials.

During the process of coal ash dissolution, other compounds can interfere with the synthetic process, e.g., iron in $\mathrm{NaOH}$ solutions can form oxides. Due to the partial dissolution of the starting material, the formation of zeolite crystals was favored on the surfaces of the coal ash particles. This can be observed in Figure 2, which shows micrograph images for a sample synthesized using the standard method at a temperature of $353 \mathrm{~K}$ for the dissolution of the coal ash.

In Figure 2 a, the characteristic cubic crystals of zeolite A with sizes between 1-1.5 $\mu \mathrm{m}$ can be observed, with the presence of other morphologies attributed to the presence of an impurity phase (Sodalite). In Figure $2 b$, the presence of crystals corresponding to zeolite A were not identified.

The crystallization time for the method with the addition of heat in step 3 was studied. Figure 3 presents the results of a crystallization time study for zeolite A over 1, 3 and 4 hours growth time.

The relative crystallinity of this material was calculated by Equation 1. The zeolite obtained at 4 hours was considered as a standard for comparison. The diffraction angles used were: $2 \theta=7.2^{\circ}, 12.5^{\circ}, 16.1^{\circ}, 21.7^{\circ}, 30^{\circ}$ and $34.2^{\circ}$.

$\%$ crystallinity $=\frac{\text { XRD peak intensity of sample }}{\text { XRD peak intensity of standard }} \times 100$
The crystallinity values obtained for the samples crystallized in 1 hour and 3 hours were 68 and 94\% respectively. The sample synthesized by the standard method showed the lowest percentage crystallinity of $37 \%$, when compared to the sample synthesized by the method with the addition of heat in the third step of synthesis.

The time study showed that with a growth time of 4 hours, the product formed is more crystalline, and even after 1 hour, the product is better than using the standard synthesis.

The formation of cubic crystals can be observed in Figure $3 \mathrm{a}$. With increasing crystallization time, the crystals become more defined and are produced in higher yield (Figure 3c). The crystals have an approximate size of $2.5 \mu \mathrm{m}$, which is consistent with zeolites synthesized in other studies ${ }^{15}$.

These synthesized materials have specific surface areas (BET method) of 42.58 (ZA 1 hour), 35.57 (ZA 3 hours) and $32.35 \mathrm{~m}^{2} / \mathrm{g}^{-1}$ (ZA 4 hours). The BET areas found for these materials are low but are still higher than the specific surface areas found for zeolites following a conventional synthesis $(\mathrm{NaA})\left(5 \mathrm{~m}^{2} / \mathrm{g}^{-1}\right)^{12} . \mathrm{N}_{2}$ adsorption measurements are not suitable for measuring the surface area of zeolite A, because $\mathrm{NaA}$ has limited adsorption capacity for nitrogen molecules ${ }^{13}$ due its pore size. However, this analysis can be used as an indication of crystallinity (the areas around $5 \mathrm{~m}^{2} / \mathrm{g}$ are indicative of zeolite $\mathrm{NaA}$ ). The specific surface area decreases with increasing synthesis time. This also indicates that longer crystallization times contribute to the formation of more crystalline materials. Zeolites synthesized from one material constituted of different cations (as coal ash) may have structures with different pore sizes and thus different surface areas.
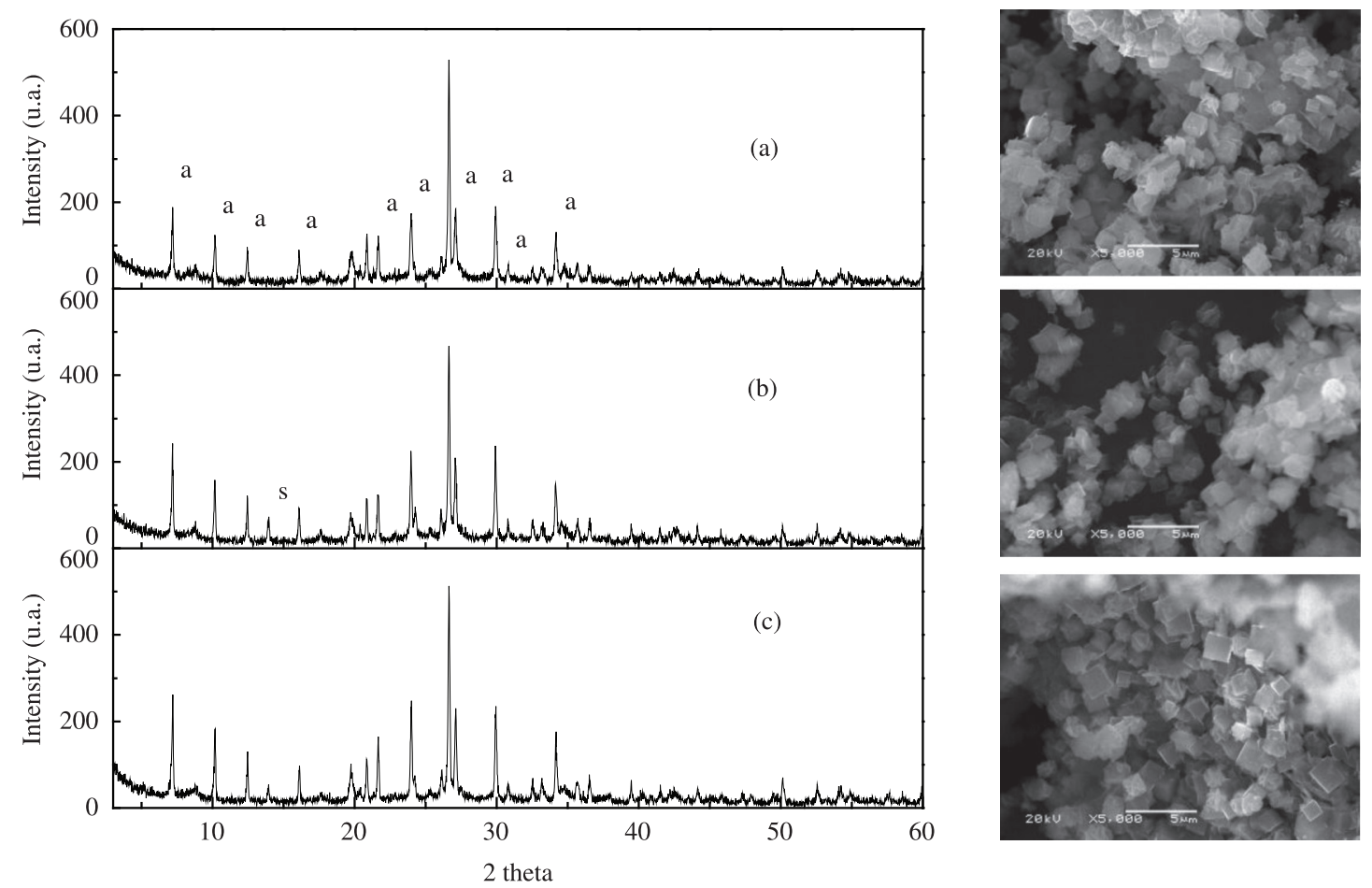

Figure 3. XRD diffractograms and SEM micrographs of zeolite A synthesized at different times: (a) 1 hour, (b) 3 hours and (c) 4 hours. 


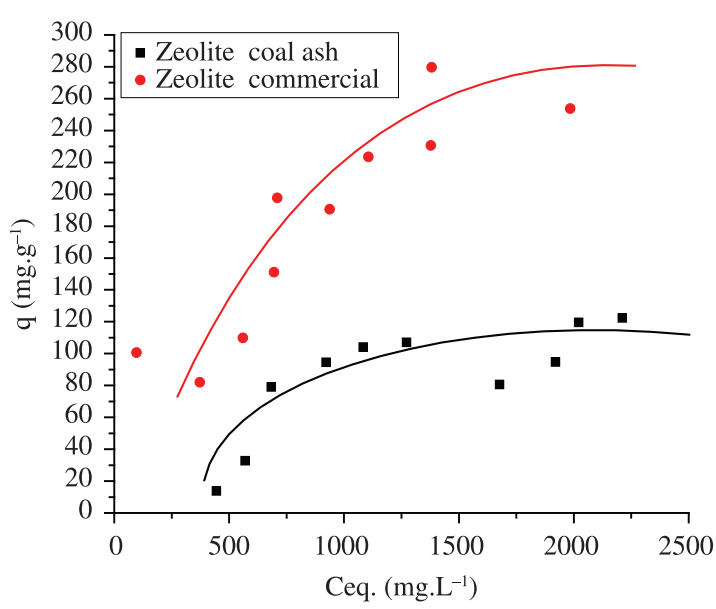

Figure 4. Adsorption isotherms of $\mathrm{Ca}^{2+}$ for zeolite A.

In this study, no separation of the $\mathrm{Si}$ and $\mathrm{Al}$ present in the ash or in its residue was performed, where this was necessary in other works ${ }^{14,15}$. The ash was used as is in the synthetic process, and the product formed contained impurities such as illite and quartz from the starting material.

\section{3. $\mathrm{Ca}^{2+}$ adsorption tests}

The zeolite A (ZA 4 hours) synthesized in this study was subjected to calcium absorption tests, and these results were compared with those of a commercial zeolite. Figure 4 shows the $\mathrm{Ca}^{2+}$ adsorption isotherms for both zeolites.

The estimated adsorption capacity was approximately $300 \mathrm{mg} \cdot \mathrm{g}^{-1}$ for the $\mathrm{Ca}^{2+}$ ion using the commercial zeolite A and approximately $120 \mathrm{mg} \cdot \mathrm{g}^{-1}$ for the synthesized zeolite A. Both zeolites have favorable adsorption isotherms for the adsorption of calcium. The low exchange capacity for $\mathrm{Ca}^{2+}$ ions is due to low crystallinity of the materials obtained in relation to commercial zeolite. Additionally, the samples were previously in $\mathrm{Na}$ form and all the cations present could be exchange with $\mathrm{Ca}$.

\subsection{Pigment synthesis}

Two zeolite A samples (commercial and synthesized) were tested for their use in the production of inorganic pigments. One example of these pigments that is commercially available is in the blue ultramarine pigments that have crystal structures based on the zeolite sodalite - $\mathrm{Na}$. The blue color is due to the encapsulation of sulfur by the sodalite structure ${ }^{16}$.

From the images in Figure 5, a difference in the color obtained by the commercial zeolite A in comparison with the synthesized zeolite A can be observed, where the

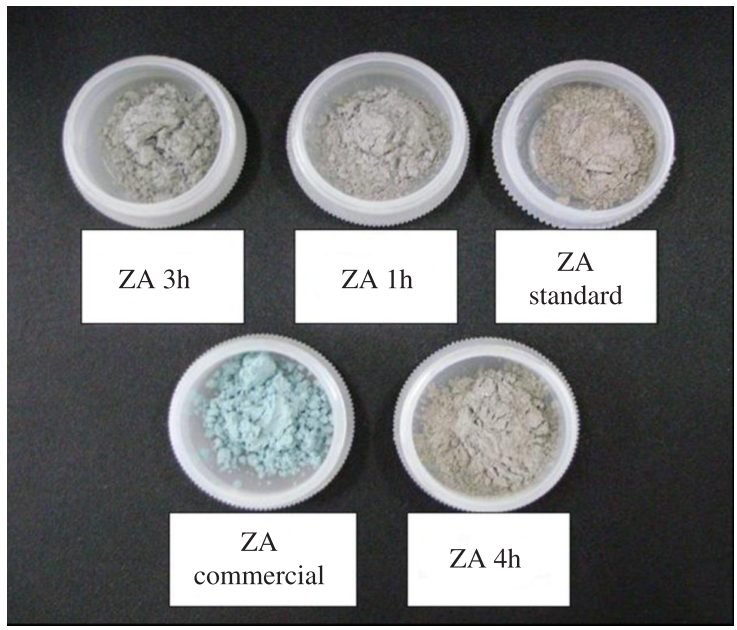

Figure 5. Images of pigments synthesized from zeolite A.

synthesized zeolites have a grayish beige color. The presence of different compounds in the precursor material may make the encapsulation of sulfur more difficult, and as a result, the desired color was not obtained.

\section{Conclusion}

It is shown that a sub-product of coal ash can be converted to zeolite A using a simple synthetic methodology. It was necessary to modify the standard IZA synthesis by increasing the reaction temperature and time to facilitate the dissolution of $\mathrm{Al}$ and $\mathrm{Si}$ species. While the presence of undissolved $\mathrm{Si}$ (quartz) was observed, it was still possible to synthesize zeolite A, as verified by XRD and SEM analysis.

In $\mathrm{Ca}^{2+}$ ion adsorption tests, the zeolite $\mathrm{A}$ synthesized under optimal conditions (353 K over a 2 hours reaction time) showed approximately half the adsorption capacity of commercially available zeolite A. It was not possible to obtain blue or green pigments using the synthesized zeolite A due to the presence of impurities in the precursor material.These results are promising because the coal ash was fully utilized during synthesis and no pre-treatment of the material was required to facilitate the separation of $\mathrm{Si}$ and Al. Therefore, the generation of by-products (waste) was avoided.

\section{Acknowledgments}

The authors would like to thank the Universidade Regional Integrada do Alto Uruguai e das missões URI, Campus Erechim, as well as the CAPES for financial support through a scholarship. 


\section{References}

1. Fungaro DA and Silva MG. Utilização de zeólita preparada a partir de cinza residuária de carvão como adsorvedor de metais em água. Química Nova. 2002; 25(6B):1081-1085. http:// dx.doi.org/10.1590/S0100-40422002000700007

2. Steenbruggen G and Hollman GG. The synthesis of zeolites from fly ash and the properties of the zeolite products. Journal of Geochemical Exploration. 1998; 62:305-309. http://dx.doi. org/10.1016/S0375-6742(97)00066-6

3. Tanaka H, Eguchi H, Fujimoto S and Hino R. Two-step process for synthesis of a single phase Na-A zeolite from coal fly ash by dialysis. Fuel. 2006; 85:1329-1334. http://dx.doi.org/10.1016/j. fuel.2005.12.022

4. Molina A and Poole C. A comparative study using two methods to produce zeolites from fly ash. Materials Engineering. 2004; 17:167-173.

5. Yaping YE, Xiaoqiang Z and Weilan Q, Mingwen W. Synthesis of pure zeolites from supersaturated silicon and aluminum alkali extracs from fused coal fly ash. Fuel. 2008; 87:1880-1886. http://dx.doi.org/10.1016/j.fuel.2007.12.002

6. Berkgaut $\mathrm{V}$ and Singer A. High capacity cation exchanger by hydrothermal zeolitization of coal fly ash. Applied clay science. 1996; 10:369-378. http://dx.doi. org/10.1016/0169-1317(95)00033-X

7. Shih W-H and Chang H-L. Conversion of fly ash into zeolites for ion-exchange applications. Materials Letters 1996; 28:263-268. http://dx.doi.org/10.1016/0167-577X(96)00064-X

8. Chareonpanich M, Namto T, Kongkachuichay P and Limtrakul J. Synthesis of ZSM-5 zeolite from lignite fly ash and rice husk ash. Fuel processing technology. 2004; 85:1623-1634. http:// dx.doi.org/10.1016/j.fuproc.2003.10.026

9. Kordatos K. Gavela S, Ntziouni A, Pistiolas KN and Kasselouri-Rigopoulou V. Synthesis of highly siliceous
ZSM-5 zeolite using sílica from Rice husk ash. Microporous and Mesopouros Materials. 2008; 115:189-196. http://dx.doi. org/10.1016/j.micromeso.2007.12.032

10. Fungaro DA and Isidoro JC. Remediação de drenagem ácida de mina usando zeólitas sintetizadas a partir de cinzas leves de carvão. Química Nova. 2006; 29(4):735-740. http://dx.doi. org/10.1590/S0100-40422006000400019

11. Ngamcharussrivichai C, Chatratananon C, Nuntang S and Prasassarakich P. Adsorptive removal of thiophene and benzothiophene over zeolites from Mae Moh coal fly ash. Fuel. 2008; 87:2347-2351. http://dx.doi.org/10.1016/j. fuel.2007.10.003

12. Rigo RT and Pergher SBC. Um novo procedimento de síntese da zeólita A empregando argilas naturais. Química Nova. 2009; 32(1):21-25. http://dx.doi.org/10.1590/ S0100-40422009000100004

13. Giannetto GP, Rendón AM and Fuentes GR. Zeolitas: Características, propiedades y aplicaciones industriales. 2nd ed. Caracas: EdIT; 2000. p. 352.

14. Walek TT, Saito F and Qiwu Z. The effect of low solid/ liquid ratio on hydrothermal synthesis of zeolites from fly ash. Fuel. 2008; 87:3194-3199. http://dx.doi.org/10.1016/j. fuel.2008.06.006

15. Wang C-F, Li J-S, Wang L-J and Sun X-Y. Influence of $\mathrm{NaOH}$ concentrations on synthesis of pure-form zeolite A from fly ash using two-stage method. Journal of Hazardous Materials. 2008; 155:58-64. http://dx.doi.org/10.1016/j. jhazmat.2007.11.028

16. Gobeltz-Hautecoeur N, Demortier A, Lede B, Lelieur JP and Duhayon C. Occupancy of the sodalite cages in the blue ultramarine pigments. Inorganic Chemistry. 2002; 41:2848-2854. http://dx.doi.org/10.1021/ ic $010822 \mathrm{c}$ 